ORIGINAL ARTICLE

\title{
Child Care among Primiparous and Multiparous Women in a Birth Cohort Study
}

\section{Flávia Françoso Genovesi ${ }^{1}$, Rosângela Aparecida Pimenta Ferrari², Sandra Mara Maciel ${ }^{3}$, José Carlos Dalmas ${ }^{4}$, Alexandrina Aparecida Maciel Cardelli ${ }^{2}$ and Débora Fernanda Vicentini Bauer ${ }^{1 *}$}

\author{
${ }^{1}$ Health Sciences Center, State University of Londrina-Paraná, Brazil \\ ${ }^{2}$ Department of Nursing, State University of Londrina-Paraná, Brazil \\ ${ }^{3}$ Department of Dentistry, State University of Maringá-Paraná, Brazil \\ ${ }^{4}$ Department of Mathematics, State University of Londrina-Paraná, Brazil
}

*Corresponding author: Débora Fernanda Vicentini Bauer, Nurse, Master's Degree Student by the Graduate Program in Nursing, Health Sciences Center, State University of Londrina-Paraná, Brazil, E-mail: devicentini@yahoo.com.br

\begin{abstract}
Objective: To analyze child care among primiparous and multiparous women in the first 42 days after childbirth.

Method: Longitudinal study with 357 postpartum women and their children. Interviews were conducted at the public maternity hospital and at 42 days after childbirth. Descriptive analyzes were used, as well as Q-square test and $p<0.05$.

Results: There was a statistical association was found between age group $(p<0.0001)$, schooling $(p<0.0001)$ and parity. Primiparity among young women $(78.3 \%)$ and schooling $\geq 8$ years $(85.3 \%)$, having a partner $(p=0.039)$, paid occupation (42.5\%) and upper and middle classes (22\%). Almost all women from both groups had exclusively breastfed in the maternity hospital ( $p=0.071)$, but $57.3 \%$ of the primiparous mothers had abandoned breastfeeding after 42 days and they had more problems in breastfeeding in the maternity hospital $(p=0.001)$ and after discharge ( $p$ $=0.007$ ), when compared to multiparous women. Difficulties in caring for the newborn were more frequent among primiparous $(79.7 \%)$ than multiparous mothers $(65.6 \%)$ use of herbal baths against jaundice (46.4\%), maternal milk against conjunctivitis (52.6\%) and sleeping together with the baby $(38.8 \%)$ were more common among multiparous women, the use of non-recommended substances in the umbilical cord stump (37.5\%) and tea against abdominal colic $(49 \%)$, as indicated by relatives, $(82.6 \%)$ were more common among primiparous women.

Conclusion: Child care among primiparous mothers has shown to be more fragile in some aspects when compared to multiparous mothers, but each group has its singularity and must receive comprehensive care, despite the different conditions of parity.
\end{abstract}

\author{
Keywords \\ Child health, Parity, Postpartum period, Epidemiologic studies
}

\section{Introduction}

Child care, as established in government programs, determines that assistance must be comprehensive, with follow-up and guidelines for prevention, health promotion and early detection of diseases, with a view to reducing risks of morbidity and mortality [1].

The birth of a child is seen as a milestone not only for the mother, but for everyone involved in the process, especially in the first pregnancy. In general, this experience causes in women ambivalent feelings and emotional instability, and they become more emotional and sentimental. They may also present high expectations and feel insecure in providing care for the newborn, which makes them seek the family support network [2]. However, this support brings intergenerational influences that can jeopardize the baby's health status [3-5].

Women who experience the birth of another child often become calmer because they know the pregnancy symptoms and deal with the care of their children in a better way [6]. Besides, influence from the family may be smaller, since these women had acquired knowledge and information in the health service during the previous gestation [7].

Citation: Genovesi FF, Ferrari RAP, Maciel SM, Dalmas JC, Cardelli AAM, et al. (2017) Child Care among Primiparous and Multiparous Women in a Birth Cohort Study. Int J Womens Health Wellness 3:050. doi. org/10.23937/2474-1353/1510050

Received: February 18, 2017: Accepted: April 10, 2017: Published: April 13, 2017

Copyright: (C) 2017 Genovesi FF, et al. This is an open-access article distributed under the terms of the Creative Commons Attribution License, which permits unrestricted use, distribution, and reproduction in any medium, provided the original author and source are credited. 
Regarding the use of health services by both parity groups, studies have indicated that women experiencing primiparity use these services more often, as pregnancy is surrounded by feelings of greater care and dedication. Multiparous women have a different conception regarding this subject, especially those with low educational level and restricted socioeconomic status $[7,8]$. Therefore, exploring the needs and difficulties of the pregnant women in providing care for the new family member is of utmost importance [1].

In view of the peculiarities of women in both par- ity groups, the objective of the present study was to analyze the care of the child among primiparous and multiparous women in the first 42 days after delivery, because after birth, biological and psychic modifications occur so that the woman returns to the pre-pregnancy state. Also, new attributions of being a mother and a woman arise, thus requiring a systematic follow-up by professionals in the health services, who must consider the different contexts and family relationships for the preservation and maintenance of the infant's health status.

Table 1: Sociodemographic characterization, type of delivery, birth, rooming-in and immediate puerperal return according to parity (primiparous and multiparous women), Londrina-PR, 2016.

\begin{tabular}{|c|c|c|c|c|c|}
\hline \multirow[b]{2}{*}{ Variable } & \multicolumn{2}{|c|}{ Primiparous } & \multicolumn{2}{|c|}{ Multiparous } & \multirow[b]{3}{*}{$P$-value } \\
\hline & $\mathbf{n}$ & $\%$ & $\mathbf{n}$ & $\%$ & \\
\hline & 143 & 100 & 214 & 100 & \\
\hline \multicolumn{6}{|l|}{ Sociodemographic characterization } \\
\hline Age group (in years) & & & & & $<0.0001$ \\
\hline$\leq 24$ & 112 & 78.3 & 69 & 32.2 & \\
\hline 25 and more & 31 & 21.7 & 145 & 67.8 & \\
\hline Marital status & & & & & 0.039 \\
\hline With partner & 113 & 79 & 187 & 87.4 & \\
\hline Without partner & 30 & 21 & 27 & 12.6 & \\
\hline Schooling & & & & & $<0.0001$ \\
\hline$\leq 7$ years & 21 & 14.7 & 67 & 31.3 & \\
\hline 8 years and more & 122 & 85.3 & 147 & 68.7 & \\
\hline Occupation & & & & & 0.583 \\
\hline Paid & 56 & 39.2 & 91 & 42.5 & \\
\hline Unpaid & 87 & 60.8 & 123 & 57.5 & \\
\hline Social class ${ }^{1}$ & & & & & 0.072 \\
\hline Upper and Middle & 20 & 14 & 47 & 22 & \\
\hline Low and Very low & 123 & 86 & 167 & 78.8 & \\
\hline \multicolumn{6}{|l|}{ Childbirth and birth } \\
\hline Type of delivery & & & & & 0.62 \\
\hline Vaginal & 109 & 76.2 & 157 & 73.4 & \\
\hline Surgery & 34 & 23.8 & 57 & 26.6 & \\
\hline Gestational age at birth & & & & & 0.493 \\
\hline$<37$ weeks & 5 & 3.2 & 4 & 1.9 & \\
\hline$\geq 37$ weeks & 138 & 96.5 & 210 & 98.1 & \\
\hline Newborn Weight (in grams) & & & & & 0.223 \\
\hline Up to 2499 & 4 & 2.8 & 2 & 0.9 & \\
\hline$\geq 2500$ & 139 & 97.2 & 212 & 99.1 & \\
\hline Apgar at $5^{\text {th }}$ minute & & & & & 0.401 \\
\hline 1 to 6 & 1 & 0.7 & - & - & \\
\hline$\geq 7$ & 142 & 99.3 & 214 & 100 & \\
\hline \multicolumn{6}{|l|}{ Rooming-in } \\
\hline Exclusive breastfeeding & & & & & 0.071 \\
\hline Yes & 133 & 93 & 208 & 97.2 & \\
\hline No & 10 & 7 & 6 & 2.8 & \\
\hline Problems with breastfeeding & & & & & 0.001 \\
\hline Yes & 57 & 39.9 & 50 & 23.4 & \\
\hline No & 86 & 60.1 & 164 & 76.6 & \\
\hline Guidance on puerperal return at discharge & & & & & 0.306 \\
\hline Yes & 116 & 81.1 & 183 & 85.5 & \\
\hline No & 27 & 18.9 & 31 & 14.5 & \\
\hline \multicolumn{6}{|l|}{ Immediate puerperal return visit } \\
\hline Yes & 92 & 64.3 & 130 & 60.7 & 0.506 \\
\hline No & 51 & 35.7 & 84 & 39.3 & \\
\hline
\end{tabular}

'Brazilian Association of Research Companies (ABEP), year 2012. 


\section{Method}

This is a longitudinal study carried out from July to November 2013 in the city of Londrina-Paraná, Brazil. The access to the women was held in the public maternity hospital of the municipality, which is a reference for average and intermediate risk pregnancies, with exclusive care by the Unified Health System (SUS).

In order to obtain the study population, a sample calculation was performed from the 3,415 births of the year 2012 , considering a margin of error of $5 \%$ and a $95 \%$ confidence level, resulting in 358 women and their children. A mother was excluded due to the donation of her child, totaling 357 women. Inclusion criteria were: living in urban zone, being an average and intermediate risk pregnant, and being able to understand and consent to their participation in the study.

Data collection took place in the maternity ward by consulting medical records, the Pregnant Women's Booklet and through interview one day after childbirth; and at the Home Visit (HV) 42 days after delivery. Authors used a previously tested form, filled out by the researchers themselves.

The study variables included the socio demographic characterization, type of delivery, birth and daily maternal care to the child in the first 42 days of life, which were associated with parity (primiparous and multiparous). The data were processed and analyzed in the Statistical Package for the Social Sciences ${ }^{\circledR}$ by using descriptive analyzes and the Q-square test, with $\mathrm{p}$-value < 0.05 .

The study was authorized by the Municipal Health Authority and approved by the Ethics Committee of the State University of Londrina, Paraná, Brazil (CEP/UEL), number 120.13/UEL and CAAE: 19352513.9.0000.5231.

\section{Results}

Of the 357 women, $40 \%$ (143) were experiencing the birth of the first child (primiparous) and 60\% (214) had two or more children (multiparous). There was statistical association between age group $(p<0.0001)$, schooling $(p<0.0001)$ and parity. Primiparity had higher rates among young women (78.3\%) and with schooling above 8 years $(85.3 \%)$. Having a partner $(p=0.039)$, paid occupation (42.5\%) and belonging to upper and middle classes (22\%) were slightly more frequent among mothers who had two or more children (Table 1).

In both parity groups, the predominant delivery route was vaginal; almost all babies were born with gestational age $\geq 37$ weeks, weighing more than 2,500 grams and with Apgar score $\geq 7$. After birth, the infants were referred to the Rooming-in (RI), and Exclusive Breastfeeding (EBF) occurred for $97.2 \%$ of the multiparous and $93 \%$ of the primiparous women. Parity was significantly associated with the report of problems for breastfeed- ing $(p=0.001)$, in which primiparous women had more problems (39.9\%) than the multiparous ones (23\%).

At hospital discharge, the professionals' recommendations for puerperal return were less frequent for primiparous women $(81.1 \%)$ than for multiparous women (85.5\%); however, a little more than $60 \%$ of them attended the said appointment in the maternity outpatient clinic under study.

Multiparous women attended more frequently the appointments with the pediatrician (77.1\%) and the nurse (71.5\%) at the Basic Health Unit (BHU), while among primiparous mothers the rates of attendance to appointments with pediatrician and nurse were $70.6 \%$ and $67.8 \%$, respectively (Table 2).

Almost all of the primiparous women's children had neonatal screening and vaccination tests updated, while among the multiparous women there was failure of 5.5\% in the tests and $3.3 \%$ in vaccination.

Regarding umbilical stump care, although had been done in both groups, $10.5 \%$ of the primiparous women did not perform it $(p=0.005)$. Hygiene with soap and water was higher among mothers with two or more children $(70 \%)$, whereas those with one child had used alcohol or saline solution (37.5\%), as well as other types of non-recommended solutions, such as coin, edible oil, spider web, etc. $(5.1 \%)(p=0.009)$.

More than $64 \%$ said they did not perform eye hygiene. Approximately $70 \%$ of the primiparous women reported using ointments to prevent dermatitis in their babies, compared to $62.1 \%$ of the multiparous women. Almost $40 \%$ of mothers with two or more children stated that the child slept in bed with their parents, whereas for those with one child, this rate was $29.4 \%$.

Offering a pacifier to calm the child also had a significant association with parity; it was $15.9 \%$ more frequent among primiparous mothers $(p=0.004)$.

Less than half of the infants in both parity groups were in Exclusive Breastfeeding (EBF), of whom 42.7\% were children of primiparous and $48.6 \%$ of multiparous mothers. Mothers with the first child (63.6\%) reported more problems with breastfeeding than those with two or more $(49.1 \%)(p=0.007)$.

Difficulties to adapt to the routine of care with the baby were more frequently mentioned by the primiparous ones (79.7\%) when compared to the multiparous ones $(65.6 \%)(p<0.0001)$. The greatest difficulties for women with the first child were performing general care (28\%), dealing with crying and intestinal colic $(21 \%)$ and allying household functions and child care (19.6\%). For those with two or more children, the difficulties were allying household functions with the care of their child (22.9\%), dealing with crying and intestinal colic (15.4\%) and waking up at night and not sleeping (13.1\%). 
Table 2: Home visit in the first 42 days after delivery: maternal daily routine of care for the child in the first 42 days of life, according to parity (primiparous and multiparous women), Londrina-PR, 2016.

\begin{tabular}{|c|c|c|c|c|c|c|}
\hline \multirow{3}{*}{ Variable } & & \multicolumn{2}{|c|}{ Primiparous } & \multicolumn{2}{|c|}{ Multiparous } & \multirow[b]{3}{*}{$P$-value } \\
\hline & & \multirow{2}{*}{\begin{tabular}{|l|}
$n$ \\
143
\end{tabular}} & \multirow{2}{*}{\begin{tabular}{|l|}
$\%$ \\
100 \\
\end{tabular}} & \multirow{2}{*}{\begin{tabular}{|l|}
$n$ \\
214
\end{tabular}} & \multirow{2}{*}{\begin{tabular}{|l|}
$\%$ \\
100 \\
\end{tabular}} & \\
\hline & & & & & & \\
\hline \multicolumn{7}{|l|}{ Easy adaptation to daily routine of care } \\
\hline \multicolumn{2}{|l|}{ Yes } & 62 & 43.4 & 107 & 50 & 0.235 \\
\hline \multicolumn{2}{|l|}{ No } & 81 & 56.6 & 107 & 50 & \\
\hline \multicolumn{7}{|l|}{ Consultation with pediatrician } \\
\hline \multicolumn{2}{|l|}{ Yes } & 101 & 70.6 & 165 & 77.1 & 0.175 \\
\hline \multicolumn{2}{|l|}{ No } & 42 & 29.4 & 49 & 22.9 & \\
\hline \multicolumn{7}{|l|}{ Nursing appointment } \\
\hline \multicolumn{2}{|l|}{ Yes } & 97 & 67.8 & 153 & 71.5 & 0.481 \\
\hline \multicolumn{2}{|l|}{ No } & 46 & 32.2 & 61 & 28.5 & \\
\hline \multicolumn{7}{|l|}{ Neonatal screening tests } \\
\hline \multicolumn{2}{|l|}{ Complete } & 142 & 99.3 & 203 & 94.5 & 0.407 \\
\hline \multicolumn{2}{|l|}{ Incomplete } & 1 & 0.7 & 11 & 5.5 & \\
\hline \multicolumn{7}{|l|}{ Vaccination } \\
\hline \multicolumn{2}{|l|}{ Complete } & 143 & 100 & 207 & 96.7 & 1.000 \\
\hline \multicolumn{2}{|l|}{ Incomplete } & - & - & 7 & 3.3 & \\
\hline Daily child care by the mother & & & & & & \\
\hline Body bath & Yes & 133 & 93 & 209 & 97.7 & 0.056 \\
\hline & No & 10 & 7 & 5 & 2.3 & \\
\hline Umbilical stump dressing & Yes & 128 & 89.5 & 208 & 97.2 & 0.005 \\
\hline & No & 15 & 10.5 & 6 & 2.8 & \\
\hline & Water and soap & 78 & 57.4 & 147 & 70 & 0.009 \\
\hline Used solution & Alcohol $70 \%$ or SS $0.9 \%$ & 51 & 37.5 & 61 & 29 & \\
\hline & Others (coin, oil etc.) & 7 & 5.1 & 2 & 1 & \\
\hline Eye hygiene & Yes & 47 & 32.9 & 76 & 35.5 & 0.650 \\
\hline & No & 96 & 67.1 & 138 & 64.5 & \\
\hline Ointment to prevent dermatitis & Yes & 99 & 69.2 & 133 & 62.1 & 0.176 \\
\hline & No & 44 & 30.8 & 81 & 37.9 & \\
\hline Sleeping together with the baby & Yes & 42 & 29.4 & 83 & 38.8 & 0.071 \\
\hline & No & 101 & 70.6 & 131 & 61.2 & \\
\hline Use of pacifier to calm the baby & Yes & 83 & 58 & 90 & 42.1 & 0.004 \\
\hline & No & 60 & 42 & 124 & 57.9 & \\
\hline Current child nutrition & & & & & & \\
\hline Exclusive breastfeeding & & 61 & 42.7 & 104 & 48.6 & 0.281 \\
\hline Artificial feeding & & 82 & 57.3 & 110 & 51.4 & \\
\hline Report of problems on breastfeeding & & & & & & \\
\hline Yes & & 91 & 63.6 & 105 & 49.1 & 0.007 \\
\hline No & & 52 & 36.4 & 109 & 50.9 & \\
\hline Difficulties to adapt to the routine of & are & & & & & \\
\hline Waking up at night and not sleeping & & 16 & 11.2 & 28 & 13.1 & $<0.0001$ \\
\hline Performing general care & & 40 & 28 & 24 & 11.2 & \\
\hline Dealing with intestinal colic and crying & & 30 & 21 & 33 & 15.4 & \\
\hline Allying functions: home and baby care & & 28 & 19.6 & 49 & 22.9 & \\
\hline No difficulties & & 29 & 20.3 & 80 & 37.4 & \\
\hline
\end{tabular}

Among the most common physiological changes occurred in the first 42 days postpartum of the child, the tegumentary system was highlighted (Table 3 ), especially the jaundice for the children of both maternal groups. In addition to the phototherapy treatment, the mothers used alternative therapies (herbal bath), which were more frequent among multiparous women (46.4\%) than primiparous women (39.1\%).
Intestinal colic in the newborn was identified more frequently $(67.8 \%)$ by the primiparous ones. Almost half $(49 \%)$ of the primiparous women used tea to relieve their child's colic, while among the multiparous ones this rate was $35 \%$. The use of tea was indicated predominantly by relatives, as referred by $82.6 \%$ of primiparous and $67.6 \%$ of multiparous women. Both parity groups also administered medication guided by health professionals. 
Table 3: Home visit in the first 42 days after delivery: ways of maternal care to the child with physiological changes of the systems according to parity (primiparous and multiparous women), Londrina-PR, 2016.

\begin{tabular}{|c|c|c|c|c|c|}
\hline \multirow{3}{*}{ System } & \multicolumn{2}{|c|}{ Primiparous } & \multicolumn{2}{|c|}{ Multiparous } & \multirow{3}{*}{$P$-value } \\
\hline & & \multirow{2}{*}{\begin{tabular}{|l|}
$\%$ \\
100 \\
\end{tabular}} & \multirow{2}{*}{$\begin{array}{l}n \\
214\end{array}$} & \multirow{2}{*}{\begin{tabular}{|l|}
$\%$ \\
100 \\
\end{tabular}} & \\
\hline & & & & & \\
\hline \multicolumn{6}{|l|}{ Tegumentary system } \\
\hline \multicolumn{6}{|l|}{ Jaundice } \\
\hline Yes & 64 & 44.8 & 97 & 45.3 & \multirow[t]{2}{*}{1.000} \\
\hline No & 79 & 55.2 & 117 & 54.7 & \\
\hline \multicolumn{6}{|l|}{ Treatment of jaundice } \\
\hline Phototherapy/sunbathing & 37 & 57.8 & 51 & 52.6 & \multirow[b]{3}{*}{0.454} \\
\hline Herbal bath & 25 & 39.1 & 45 & 46.4 & \\
\hline Tea & 2 & 3.1 & 1 & 1 & \\
\hline \multicolumn{6}{|l|}{ Gastrointestinal system } \\
\hline \multicolumn{6}{|l|}{ Intestinal colic } \\
\hline Yes & 97 & 67.8 & 121 & 56.5 & \multirow[t]{2}{*}{0.036} \\
\hline No & 46 & 32.2 & 93 & 43.5 & \\
\hline \multicolumn{6}{|l|}{ Use of teas for intestinal colic } \\
\hline Yes & 70 & 49 & 75 & 35 & \multirow[t]{2}{*}{0.011} \\
\hline No & 73 & 51 & 139 & 65 & \\
\hline \multicolumn{6}{|c|}{ Who advised to use teas for intestinal colic } \\
\hline Healthcare professional & 2 & 2.9 & 2 & 2.7 & \multirow[b]{3}{*}{0.091} \\
\hline Individual option & 11 & 14.5 & 23 & 29.7 & \\
\hline Relatives & 57 & 82.6 & 50 & 67.6 & \\
\hline \multicolumn{6}{|c|}{ Use of medication for intestinal colic } \\
\hline Yes & 38 & 26.6 & 51 & 23.8 & \multirow[t]{2}{*}{0.618} \\
\hline No & 105 & 73.4 & 163 & 76.2 & \\
\hline \multicolumn{6}{|c|}{ Who directed medication for intestinal colic } \\
\hline Healthcare professional & 35 & 92.1 & 39 & 78.0 & \multirow[b]{3}{*}{0.079} \\
\hline Individual option & 1 & 2.6 & 9 & 18 & \\
\hline Relatives & 2 & 5.3 & 2 & 4 & \\
\hline \multicolumn{6}{|l|}{ Ophthalmic system } \\
\hline Conjunctivitis/ocular secretio & & & & & \\
\hline Yes & 47 & 32.9 & 76 & 35.5 & \\
\hline No & 96 & 67.1 & 138 & 64.5 & 0.650 \\
\hline Treatment for conjunctivitis/c & & & & & \\
\hline Eye drops or saline solution & 29 & 61.7 & 36 & 47.4 & 0.292 \\
\hline Breast milk & 18 & 38.3 & 40 & 52.6 & \\
\hline Respiratory system & & & & & \\
\hline Nasal obstruction & & & & & \\
\hline Yes & 76 & 53.1 & 144 & 53.3 & 1.000 \\
\hline No & 67 & 46.9 & 100 & 46.7 & \\
\hline Flu, cold, pneumonia & & & & & \\
\hline Yes & 12 & 8.3 & 21 & 9.8 & 0.718 \\
\hline No & 131 & 91.6 & 193 & 90.2 & \\
\hline
\end{tabular}

The presence of conjunctivitis/ocular secretion in infants was reported by $32.9 \%$ of the primiparous and $35.5 \%$ of the multiparous mothers. The use of eye drops or saline solution for treatment totaled $61.7 \%$ and $47.4 \%$, respectively. The use of breast milk was more frequent among mothers with two or more children (52.6\%), compared to those with one child (38.3\%).
Among respiratory problems, more than $53 \%$ of both groups reported nasal obstruction, cold/flu/pneumonia by $8.3 \%$ of the primiparous women and $9.8 \%$ of multiparous women.

\section{Discussion}

The reproductive age and socioeconomic status of the women in the studied municipality did not follow the na- 
tional trend, since in the South and Southeast regions the age of delivery of women was $\geq 30$ years of age with $>12$ years of education, in the North and Northeast regions, $\leq$ 20 years of age with less than seven years of education [9].

Regarding the type of delivery, even though the maternity hospital under study meets average and intermediate risk pregnancies, the surgical route was used in more than $20 \%$ of the deliveries. In Brazil, there has been an increase in cesarean sections without a proper indication, contrary to the recommendation of the World Health Organization, of a maximum of $15 \%$ [10].

After delivery, not all the infants were in EBF, and the primiparous mothers reported more difficulty in breastfeeding, although the studied maternity hospital had received the title of Children's Hospital Initiative (IHAC in Portuguese). A similar result was identified in a hospital with the title of IHAC, in São Paulo, Brazil [11]. Researchers revealed that, regardless of obstetric conditions, one-third of the primiparous and multiparous women with or without experience who sought to breastfeed failed to initiate it, which requires educational efforts directed towards support for both groups [12].

At hospital discharge, although most of the puerperal women were guided to the puerperal return visit, some of them did not attend. When analyzing the frequency per parity group, it was lower among the multiparous women. On the other hand, the frequency in the appointments for the children of this group of women was slightly higher. Despite of this, in the ministerial guidelines, the follow-up of women and children is a priority and fundamental action to identify complications and intervene early [1].

In Haiti, women with higher numbers of children have more frequently discontinued follow-up at the health service [7]. In Brazil, this result was similar, as well as low maternal schooling [13]. Among the reasons for the low adherence to follow-up in the health service there were the lack of awareness and considering it unnecessary [13], lack of staff, lack of medications and precarious structure [14], forgetfulness and lack of time [15].

Researchers have also pointed to the fragmentation of maternal and child care, since even though home visits were made to the puerperium woman and the newborn, guidelines were directed almost exclusively to one of them $[16,17]$. Besides this fragmentation, the actions performed were not effective $[13,18]$.

Postpartum women of both parity groups attended more frequently to their child's appointments. However, maternal practices without scientific evidence and popularly disseminated have been observed. These practices, such as putting coin, spider web, edible oil, etc. in the umbilical stump appear to be consolidated among the family generations and may pose risks to the baby's health. Similar results have been found in other studies in the country $[19,20]$. On the other hand, the use of $70 \%$ alcohol in the care for the umbilical stump is not a consensus, but a study in Bangladesh showed that the prevention of infections and neonatal death was lower in the group that applied chlorohexidine at birth, compared to the group that used it daily for seven days [21].

Regarding maternal skin care, the use of ointments to prevent dermatitis was indiscriminate, but a study identified that the components of the formulas, in general, present toxic chemical agents because they are cosmetological products and are not recommended for use in children during the neonatal and infantile period. Therefore, parents and professionals should not surrender to the marketing appeal of these products, but reject them so that risks of dermatological diseases are minimized [22].

The practice of mothers sleeping together with the baby was also evidenced in the present study, being more frequent among multiparous women. A similar result was found in a study carried out in Pelotas-RS, Brazil [23]. Nevertheless, these authors defend that there are cognitive benefits as well as the maintenance of exclusive breastfeeding when the mother sleeps together with the neonate.

Regarding exclusive breastfeeding, abandonment was evidenced in this study in the first 42 days of the child's life, being a little more frequent among primiparous women. Researchers have shown that many mothers have difficulties such as: lack of knowledge, problems with breasts, weak milk and lack of milk $[4,24]$. The use of pacifiers to calm the baby was also observed [4]. The pacifier was common among the parity groups of this study, being a little more common among primiparous women. This group also reported more difficulty in breastfeeding and in adapting to the daily care of the child and to domestic and family activities in the neonatal period, which was similar to another study [25]. On the other hand, the multiparous women felt easiness in the care of the child, although more busy by having other children $[6,26]$.

Obviously, the family dynamics undergoes transformations in the daily life of both the primiparous and the multiparous mothers. Therefore, the health team must provide a quality maternal and child care, and must be present to provide support and guidance, to recognize the fragilities and potentialities of each case and to be working towards the adequate recovery of the puerperal woman and the healthy growth and development of the child $[7,8]$.

Regarding the physiological changes of children, mothers reported using complementary therapies that are not recommended and that have no scientific evidence, such as herbal baths to treat jaundice. A study showed that most of the mothers knew of some type of alternative treatment such as bath with herbs, virgin tile and white rose, as well as sun exposure. They had perception about the effectiveness or not of the practices and some reported previous use or intention to do it after hospital discharge [27]. 
Colic in the newborn, identified by the mothers in this study, is considered a natural occurrence due to intestinal immaturity [28]. It was more frequent among children of primiparous mothers, as well as the provision of teas for its relief, predominantly guided by relatives. Similar results were found in another investigation with the introduction of tea by infants' mothers even during exclusive breastfeeding period [29].

Limited management of colic by parents may put at risk the maintenance of exclusive breastfeeding. Therefore, it is necessary to provide guidance to the mother since the prenatal period, in order to make them apt to prevent colic and to provide adequate care in the relief of the child's pain [3]. Attention should also be paid to discouraging them from using teas, as this practice is rooted in popular belief that it helps in colic relief and in the relaxation of the baby, as well as the treatment of jaundice with teas and baths [25].

Similarly, the use of breast milk in the treatment of conjunctivitis ocular secretion has no scientific evidence. In general, chemical conjunctivitis occurs after the application of silver nitrate $1 \%$. Its duration is up to 48 hours and the persistence of signs and symptoms should be evaluated by a specialist [30].

The popular knowledge of previous generations, still widespread among both primiparous and multiparous women of the present study, shows how the network of family and sociocultural relationships influences child care practices [5]. However, this study points to a re-signification of this care among mothers with more children after participating in educational activities in a health service, in which they had acquired scientific knowledge and replaced the popular knowledge [8]. On the other hand, results from a research point out that a more individualized care is needed for primiparous women because they have less knowledge than the multiparous ones [30] and because they refer to feelings of fear lack of confidence, justified by the lack of experience [20].

\section{Conclusion}

Although the primiparous mothers are considered more susceptible to the erroneous accomplishment of some care actions to the newborn, a child will always bring challenges for a mother, whether it is the first child or not. Each child has their singularity, and thus, health practitioner must carry out a comprehensive care for all pregnant and puerperal women, without differentiating parity.

\section{References}

1. Ministry of Health (2013) Pregnancy, birth and birth with health, quality of life and well-being. Brasilia.

2. Zanatta E, Pereira CR (2015) "She sees in you the world": the experience of motherhood for the first time. Temas Psicol 23: 959-972.
3. Christoffel MM, Siva LR, Veiros Ferreira acg, Macedo ec (2013) Infant colic: descriptive study of maternal care practices for pain relief. Rev Enferm UFPE On line 7: 5876-5882.

4. Rocha NB, Garbin AJI, Garbin CAS, Saliba O, Moimaz SAS (2013) A Longitudinal Study on Breastfeeding and Factors Related to Early Weaning. Pesq Bras Odontoped Clin Integr 13: 337-342.

5. Linhares EF, Silva LWS, Rodrigues VP, Araujo RT (2012) Intergenerational influence on the care of newborns' umbilical stumps. Texto Contexto Enferm 21: 828-836.

6. Esteves CM, Sonego JC, Lopes RCS, Vivian AG, Piccinini CA (2013) Maternal Feelings and Expectations During Second Pregnancy. Psico 44: 542-551.

7. Babalola SO (2014) Factors associated with use of maternal health services in Haiti: a multilevel analysis. Rev Panam Salud Publ 36: 1-9.

8. Rodrigues DP, Guerreiro EM, Ferreira MA, Azevedo Queiroz AB, Costa Barbosa DF, et al. (2013) Social representations of women in pregnancy, postpartum, and educational actions. Online Braz J Nurs 12: 911-922.

9. Ministry of Health (2014) Health Brazil 2013: an analysis of the health situation and communicable diseases related to poverty. Brasilia.

10. (2015) Ministry of Health, National Commission for the incorporation of DUS technologies. Guidelines for attention to the pregnant woman: the cesarean section, Brasilia.

11. Rocci E, Fernandes RA (2014) Breastfeeding difficulties and influence in the early weaning. Rev Bras Enferm 67: 22-27.

12. Cordero L, Bajwa A, Prasad MR, Oza-Frank R, Landon M, et al. (2016) Breastfeeding at Hospital Discharge among High Risk Obstetrical Patients. Int J Womens Health Wellness 2: 31 .

13. Adhikari R (2016) Effect of women's autonomy on maternal health service utilization in Nepal: a cross sectional study. BMC Women's Health 16: 26.

14. Vitolo, Marcia Regina, Gama, Campagnolo, Paula Dal Bo (2010) Frequency of public child care service use and associated factors. J Pediat 86: 80-84.

15. Souza MHN, Gomes TNC, Paz EPA, Trindade CSV, Carvalho Veras RC, et al. (2011) A welcome strategy mother-baby - aspects related to the clientele in a basic health unit of the municipality of Rio de Janeiro. Esc Anna Nery 15: 671-677.

16. Ximenes-Neto FRG, Queiros CA, Cunha ICRO (2010) Why I don't take my child for a childcare consultation. Rev Soc Bras Enferm Ped 10: 51-59.

17. Mazzo MHSN, Brito RS, Santos (2014) FAPS Nurses' activities during postpartum home visit. Rev Enferm UERJ 22: 663-667.

18. Rodrigues DP, Dodou HD, Lago PN, Mesquita NS, Torres de Melo LP, et al. (2014) Care for both mother and child immediately after childbirth: a descriptive study. Online Braz J Nurs 13: 227-238.

19. Lima PR, Furtado MCC, Reis MCG, Mello DF, Pina JC (2016) Newborn access and care in a health attention program. Rev Eletr Enf 18: 1-10.

20. Pereira MC, Garcia ESGF, Andrade MBT, Gradim CVC (2012) The feelings of primiparas who have recently given birth in caring for the newborn baby. Cogitare Enferm 17: 537-542.

21. Arifeen SE, Mullany LC, Shah R, Ishtiaq Mannan, Syed M Rahma, et al. (2012) The effect of cord cleansing with chlorhexidine 
on neonatal mortality in rural Bangladesh: a community-based, cluster-randomised trial. Lancet 379: 1022-1028.

22. Fernandes JD, Machado MCR, Oliveira ZNP (2011) Children and newborn skin care and prevention. An Bras Dermatol 86: 102-110.

23. Santos IS, Mota DM, Matijasevich A (2010) Epidemiology of co-sleeping and nighttime waking at 12 months in a birth cohort. J pediatr (Rio J) 84: 114-122.

24. Brito H, Alexandrino AM, Godinho C, Santos G (2011) Breastfeeding Experience. Acta Pediatr Port 42: 209-214.

25. Bianchini CO, Kerber N (2010) Myths and beliefs regarding mother and newborn care. Vittalle 22: 35-50.

26. Luchesi BM, Beretta MIR, Dupas G (2010) Knowledge and use of alternative treatments for neonatal jaundice. Cogitare Enferm 15: 506-512.
27. Savino F, Ceratto S, Marco A, Luca Cordero di Montezemolo (2014) Looking for new treatments of infantile colic. Italian Journal of Pediatrics 40: 53.

28. Campos AMS, Chaoul CO, Carmona EV, Higa R, Nogueira do Vale I (2015) Exclusive breastfeeding practices reported by mothers and the introduction of additional liquids. Rev Latino-Am Enfermagem 23: 283-290.

29. Passos AF, Agostini FS (2011) Neonatal conjunctivitis with emphasis on its prevention. Rev Bras Oftalmol 70.

30. Ferreira MA, Ferreira GR, Parreira BDM, Soares MBO, Silva SR (2015) Mothers know about the care of children under one year. Rev Enferm Atencao Saude 4: 16-27. 